\title{
Apelin-13 induces a biphasic haemodynamic response and hormonal activation in normal conscious sheep
}

\author{
Christopher J Charles, Miriam T Rademaker and A Mark Richards \\ Christchurch Cardioendocrine Research Group, Christchurch School of Medicine and Health Sciences, Christchurch, New Zealand \\ (Requests for offprints should be addressed to C J Charles; Email: chris.charles@chmeds.ac.nz)
}

\begin{abstract}
Whilst the tissue distribution and range of biological actions reported for apelin suggest a role for the peptide in pressure/volume homeostasis, conflicting reports make the precise role unclear. Furthermore, few integrated studies have been performed and there are no reports of bioactivity of apelin in a large animal model. Accordingly, we have examined the haemodynamic, hormonal and renal effects of apelin in ten normal conscious sheep. Apelin (1 mg i.v. bolus) induced a biphasic haemodynamic response characterised by an acute fall in arterial pressure and a rise in heart rate followed immediately by a rise in arterial pressure and a fall in heart rate. The secondary hypertensive phase was associated with a fall in cardiac output $(P=0 \cdot 015)$ and significant rises in calculated total peripheral resistance (CTPR) $(P<0 \cdot 001)$ and right atrial pressure (RAP) $(P=0 \cdot 031)$. Electrocardiogram
\end{abstract}

changes were also observed in four of ten sheep, most notably varying degrees of atrioventricular block. Apelin also induced significant rises in plasma arginine vasopressin $(P=0 \cdot 009)$, adrenocorticotrophin $(P=0 \cdot 012)$, aldosterone $(P=0 \cdot 001)$, cortisol $(P=0 \cdot 014)$, atrial $(P=0 \cdot 036)$ and brain $(P<0 \cdot 001)$ natriuretic peptide, cyclic GMP $(P=0 \cdot 003)$ and cyclic AMP $(P=0.002)$ levels with no effect on renal indices. In conclusion, high dose administration of apelin to normal conscious sheep induces a significant biphasic response in arterial pressure and heart rate associated with rises in RAP and CTPR and a fall in cardiac output. Apelin also increases circulating levels of a number of vasoactive hormones. Taken together, these results suggest a potential role for apelin in pressure/volume homeostasis. Journal of Endocrinology (2006) 189, 701-710

\section{Introduction}

Apelin, a peptide recently isolated from bovine stomach extracts, appears to act as an endogenous ligand for the previously orphaned G-protein-coupled APJ receptor (Tatemoto et al. 1998). The pre-propeptide consists of 77 amino acids with mature apelin likely derived from the C-terminal region as either a 36 or a 13 amino acid peptide. Apelin mRNA and peptide expression have subsequently been described in various tissues including gastrointestinal tract, adipose tissue, brain, lung, kidney, liver and the cardiovascular system (Lee et al. 2000, Kawamata et al. 2001). Within the cardiovascular system apelin is strongly expressed in the heart (Lee et al. 2000) with expression also present in the large conduit vessels, coronary vessels and endothelial cells (Kleinz et al. 2005). Expression of mRNA for the APJ receptor is similarly distributed throughout the brain and periphery including cardiovascular tissue (Lee et al. 2000, Katugampola et al. 2001, Kleinz et al. 2005).

Haemodynamic actions have been attributed to apelin. Several studies show that the peptide lowers arterial pressure in anaesthetised (Lee et al. 2000, Tatemoto et al. 2001,
El Messari et al. 2004) and conscious (Cheng et al. 2003) rats, possibly via a nitric oxide dependent mechanism (Tatemoto et al. 2001). However, there are also contradictory reports of apelin increasing arterial pressure in conscious rats (Kagiyama et al. 2005). In ganglionblocked rats, mean circulatory filling pressure is reduced by apelin, suggesting that it is a venodilator (Cheng et al. 2003). In contrast, apelin potently constricts human saphenous veins (Katugampola et al. 2001). Other haemodynamic actions of apelin include positive inotrophic effects reported in isolated rat hearts (Szokodi et al. 2002) and an increase in the first derivative of left ventricular pressure or the rate of change in pressure with time $(\mathrm{dP} / \mathrm{dt})$ in normal and heart failure rats (Berry et al. 2004). Whilst apelin reduces preload and afterload in mice, it appears to exhibit differential acute (reduction) and chronic (increase) effects on cardiac output (Ashley et al. 2005).

The APJ receptor has also been localised in the hypothalamus and its expression responds to both osmotic and stress stimuli (O'Carroll \& Lolait 2003, O'Carroll et al. 2003). Whilst both i.p. (Lee et al. 2000) and i.c.v. (Taheri et al. 2002) administration of apelin has been shown to increase drinking, other authors have demonstrated a 
reduced drinking response to i.c.v. apelin in dehydrated rats (Reaux et al. 2001). There are conflicting reports on the effects of apelin on arginine vasopressin (AVP) secretion including increased AVP release from hypothalamic explants (Taheri et al. 2002) but reduced AVP secretion reported in vivo in response to i.c.v. apelin (Reaux et al. 2001, De Mota et al. 2004). Apelin also increases corticotrophin releasing hormone release from hypothalamic explants (Taheri et al. 2002) and increases adrenocorticotrophin (ACTH) (Taheri et al. 2002) and corticosterone (Taheri et al. 2002, Jaszberenyi et al. 2004) release in vivo.

Whilst this range of biological actions reported for apelin suggest a role for the peptide in pressure/volume homeostasis, contrasting reports make its precise role unclear. Furthermore, few integrated studies have been performed and there are no reports of bioactivity of apelin in a large animal model. Accordingly, we have examined the haemodynamic, hormonal and renal effects of apelin in normal conscious sheep.

\section{Materials and Methods}

The Animal Ethics Committee of the Christchurch School of Medicine and Health Sciences approved the study protocol. Ten Coopworth ewes weighing 44-67 kg (Lincoln University Farm, Christchurch, New Zealand) were housed in an air-conditioned light-controlled room and received a diet of lucerne chaff and food pellets providing $75 \mathrm{mmol}$ sodium and $150 \mathrm{mmol}$ potassium per day. Under general anaesthesia (induced by $17 \mathrm{mg} / \mathrm{kg}$ thiopentone sodium and maintained by a mixture of halothane, nitrous oxide and oxygen) a carotid artery was cannulated (16 G Angiocath; Becton Dickinson, Sandy, UT, USA) for direct measurement of arterial pressure and heart rate. Polyethylene catheters were placed in the jugular veins for blood sampling and measurement of right atrial pressure (RAP) and a Swan-Ganz thermodilution catheter (Edwards Life Sciences, Irvine, CA, USA) was placed in the pulmonary artery via the jugular vein for measurements of cardiac output. A foley catheter was placed per urethra in the bladder to allow continuous collection of urine. Stainless steel safety pins were placed through the skin of the four limbs for subsequent attachment of electrocardiogram (ECG) leads. The animals recovered for at least 7 days before experiments.

Each animal was studied on two occasions two days apart receiving vehicle control (0.9\% saline) and human apelin-13 (American Peptides, Sunnyvale, CA, USA). Apelin was administered in incremental doses as i.v. boli injections $(10 \mathrm{ml}$ given over $15 \mathrm{~s})$ of $10 \mu \mathrm{g}, 100 \mu \mathrm{g}$ and $1 \mathrm{mg}$ at $1-\mathrm{h}$ intervals. Control solution and apelin were administered in a balanced, random order design.

Arterial pressure, RAP and ECG were recorded using an in-house online data acquisition system, commencing $30 \mathrm{~min}$ before bolus administration and continuing for
$60 \mathrm{~min}$ beyond the last bolus. Heart rate and pressures were digitally integrated in 1-min recording periods and data were recorded at preset intervals throughout the study. Cardiac output (thermodilution) was measured in triplicate (three values within 10\%) at preset intervals for the duration of infusions. Calculated total peripheral resistance (CTPR) was calculated as mean arterial pressure (MAP) divided by cardiac output.

Venous blood was drawn at preset intervals during the study protocol. Blood was taken into chilled EDTA tubes, centrifuged and the plasma was stored at $-80{ }^{\circ} \mathrm{C}$ before assay for AVP (Sadler et al. 1983), ACTH (Donald 1977), aldosterone (Lun et al. 1983), atrial natriuretic peptide (ANP) (Charles et al. 1990), brain natriuretic peptide (BNP) (Pemberton et al. 1997), catecholamines (Goldstein et al. 1981), cortisol (Lewis et al. 1992), cyclic GMP (Charles et al. 1990), endothelin-1 (Rademaker et al. 2000), plasma renin activity (PRA) (Dunn \& Espiner 1976), urocortin (Rademaker et al. 2002) and cyclic AMP by a commercially available kit (Biotrak; Amersham). Haematocrit was measured with each blood sample.

\section{Statistical analysis}

Results are expressed as means \pm S.E.M. Two-way ANOVA with time as a repeated measure was used to determine time and treatment differences between the apelin and control arms of the study. Statistical significance was assumed at $P<0 \cdot 05$. Where significant differences were identified by ANOVA, a priori Fisher's protected least square difference (LSD) tests were used to identify timepoints significantly different from time-matched control.

\section{Results}

Experiments were completed without mishap and data collection was complete. There was no significant difference in baseline levels of any variables between study days. Furthermore, with the exception of plasma BNP, all variables were similar to time-matched controls immediately prior to each bolus.

The lower doses of apelin $(10$ and $100 \mu \mathrm{g})$ had no significant effect on haemodynamic parameters (Fig. 1). However, the $1 \mathrm{mg}$ bolus of apelin induced a significant $(P<0 \cdot 001)$ biphasic response in MAP, with an initial fall in pressure (approximately $12 \mathrm{mmHg}$ below the timematched control value at 2 min post-bolus) followed by a rise in MAP peaking approximately $12 \mathrm{mmHg}$ above the control value at $4 \mathrm{~min}$ post-bolus. These effects were short-lived with pressures returning to control levels by 15 min post-bolus. Both systolic $(P=0.015)$ and diastolic $(P<0.001)$ arterial pressures were affected similarly by the $1 \mathrm{mg}$ dose of apelin with no significant effect on pulse pressure (data not shown). Heart rate response to $1 \mathrm{mg}$ 


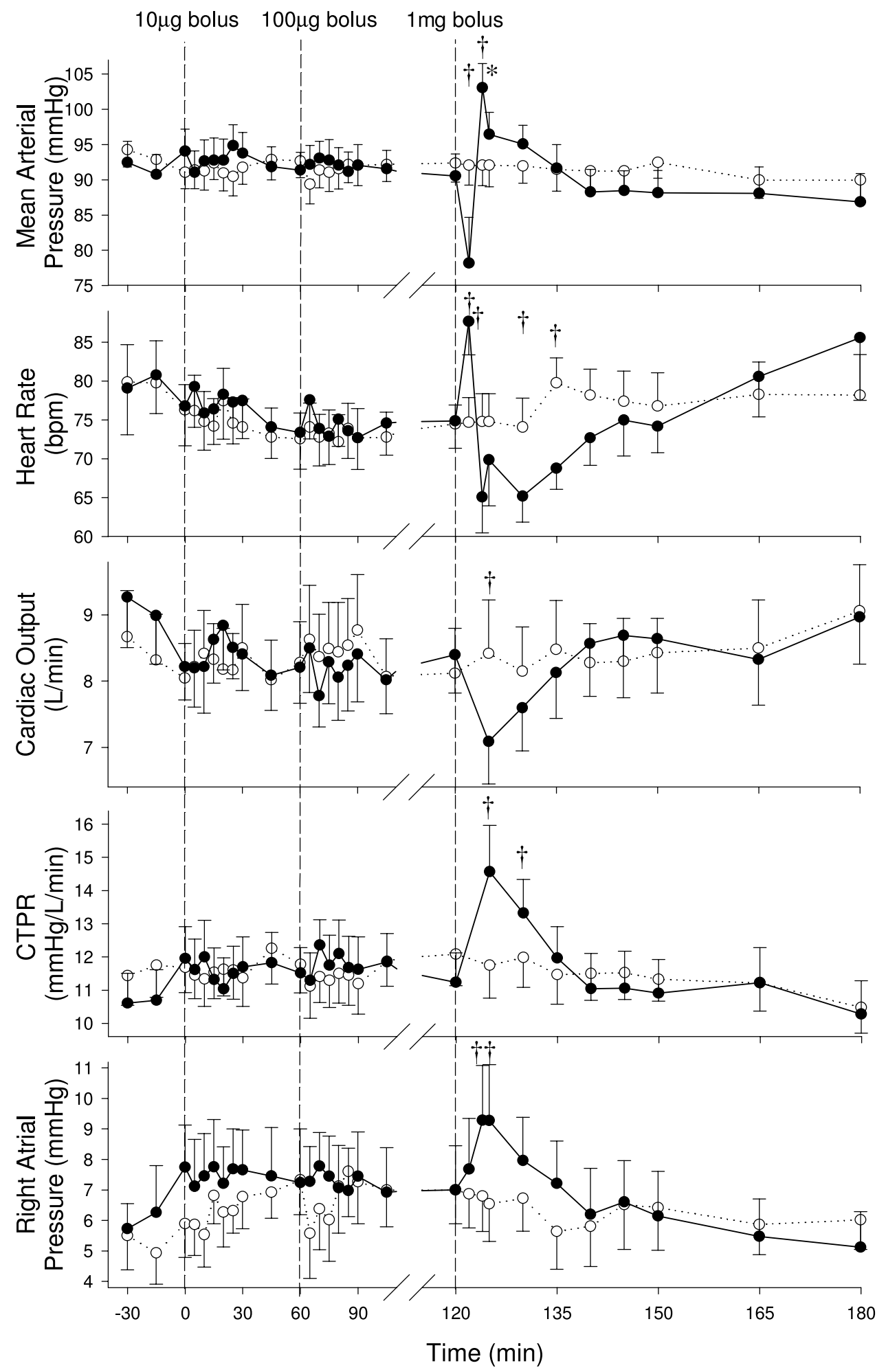

Figure 1 Haemodynamic response to i.v. bolus injections of apelin $(0)$ or vehicle control $(\bigcirc)$ in ten sheep. Values are means \pm S.E.M. Significant differences were observed for mean arterial pressure $(P<0 \cdot 001)$, heart rate $(P=0 \cdot 017)$, cardiac output $(P=0 \cdot 015)$, calculated total peripheral resistance $(C T P R)(P<0 \cdot 001)$ and right atrial pressure $(P=0.031)$. Individual time points significantly different from time-matched control (Fisher's protected LSD) are indicated by ${ }^{*} P<0 \cdot 05$ and $\uparrow P<0 \cdot 01$. 
Table 1 Haematocrit and plasma hormone responses in ten sheep to $1 \mathrm{mg}$ bolus dose of apelin or vehicle control administered at $120 \mathrm{~min}$

\begin{tabular}{|c|c|c|c|c|c|}
\hline & Baseline & $120 \mathrm{~min}$ & $135 \mathrm{~min}$ & $150 \mathrm{~min}$ & $180 \mathrm{~min}$ \\
\hline \multicolumn{6}{|c|}{ Haematocrit (\%) } \\
\hline Control & $26 \cdot 0 \pm 1 \cdot 5$ & $24 \cdot 7 \pm 1 \cdot 3$ & $24 \cdot 4 \pm 1 \cdot 3$ & $24 \cdot 2 \pm 1 \cdot 3$ & $24 \cdot 6 \pm 1 \cdot 2$ \\
\hline Apelin & $26 \cdot 2 \pm 1 \cdot 4$ & $25 \cdot 0 \pm 1 \cdot 5$ & $25 \cdot 4 \pm 1 \cdot 4$ & $24 \cdot 2 \pm 1 \cdot 6$ & $24 \cdot 9 \pm 1 \cdot 5$ \\
\hline \multicolumn{6}{|c|}{ Plasma endothelin (pmol/l) } \\
\hline Control & $1 \cdot 8 \pm 0 \cdot 2$ & $2 \cdot 1 \pm 0 \cdot 3$ & $2 \cdot 2 \pm 0 \cdot 3$ & $2 \cdot 1 \pm 0 \cdot 3$ & $2 \cdot 1 \pm 0 \cdot 3$ \\
\hline Apelin & $2 \cdot 3 \pm 0 \cdot 3$ & $2 \cdot 7 \pm 0 \cdot 3$ & $2 \cdot 7 \pm 0 \cdot 2$ & $2 \cdot 9 \pm 0 \cdot 3$ & $3 \cdot 0 \pm 0 \cdot 3$ \\
\hline \multicolumn{6}{|c|}{ Plasma renin activity $(\mathrm{nmol} / \mathrm{l} / \mathrm{h})$} \\
\hline Control & $0 \cdot 25 \pm 0 \cdot 05$ & $0 \cdot 18 \pm 0 \cdot 05$ & $0 \cdot 18 \pm 0 \cdot 05$ & $0 \cdot 18 \pm 0 \cdot 04$ & $0 \cdot 18 \pm 0 \cdot 04$ \\
\hline Apelin & $0 \cdot 22 \pm 0 \cdot 04$ & $0 \cdot 15 \pm 0 \cdot 03$ & $0 \cdot 16 \pm 0 \cdot 03$ & $0 \cdot 15 \pm 0.03$ & $0 \cdot 18 \pm 0 \cdot 04$ \\
\hline \multicolumn{6}{|c|}{ Plasma norepinephrine $(\mathrm{pmol} / \mathrm{l})$} \\
\hline Control & $6400 \pm 1380$ & $4790 \pm 930$ & $5600 \pm 1390$ & $5660 \pm 1550$ & $4870 \pm 1160$ \\
\hline Apelin & $6460 \pm 1390$ & $5700 \pm 1730$ & $5600 \pm 1200$ & $5220 \pm 1010$ & $4960 \pm 1140$ \\
\hline \multicolumn{6}{|c|}{ Plasma epinephrine (pmol/l) } \\
\hline Control & $598 \pm 99$ & $450 \pm 51$ & $467 \pm 55$ & $431 \pm 55$ & $514 \pm 69$ \\
\hline Apelin & $504 \pm 44$ & $454 \pm 89$ & $476 \pm 76$ & $441 \pm 81$ & $482 \pm 64$ \\
\hline \multicolumn{6}{|c|}{ Plasma urocortin (pmol/l) } \\
\hline Control & $16 \cdot 4 \pm 0 \cdot 9$ & $15 \cdot 1 \pm 0 \cdot 8$ & $15 \cdot 5 \pm 1 \cdot 1$ & $14 \cdot 7 \pm 0 \cdot 9$ & $14 \cdot 6 \pm 0 \cdot 3$ \\
\hline Apelin & $15 \cdot 7 \pm 0 \cdot 6$ & $15 \cdot 1 \pm 1 \cdot 1$ & $15 \cdot 3 \pm 0 \cdot 8$ & $14 \cdot 1 \pm 0 \cdot 6$ & $14 \cdot 5 \pm 0 \cdot 7$ \\
\hline
\end{tabular}

Values are means \pm S.E.M. In addition, 10 and $100 \mu \mathrm{g}$ doses were administered at 0 and 60 min respectively and had no significant effect (data not shown).

apelin was likewise biphasic $(P=0 \cdot 017)$, but was a mirror image of the response of MAP with an immediate $(2 \mathrm{~min})$ rise in heart rate followed by a fall to below control levels between 4 and 20 min post-bolus (Fig. 1). The high dose of apelin also induced a significant but short lived (peak effects 5 min post-bolus) fall in cardiac output $(P=0 \cdot 015)$ and rise in RAP $(P=0 \cdot 031)$. CTPR was also raised in response to $1 \mathrm{mg}$ apelin bolus at $5-10 \mathrm{~min}$ post-bolus $(P<0 \cdot 001)$. ECG changes, including sinus tachycardia and sudden onset of sinus bradycardia (with or without changes in arterial pressure), were observed in four out of ten sheep following the $1 \mathrm{mg}$ dose. However, the most consistent ECG change observed in these four sheep was varying degrees of atrioventricular (AV) block lasting up to $15 \mathrm{~min}$ post-bolus. Prolonged periods of 2:1 AV block were observed with 3:1 and 4:1 block also observed in one sheep. AV block was also observed in one of the sheep following the $100 \mu \mathrm{g}$ dose. Apelin had no significant effect on haematocrit (Table 1).

The response of the hypothalamic-pituitary-adrenal (HPA) axis is shown in Fig. 2. Whilst the lower two doses of apelin had no effect, the $1 \mathrm{mg}$ bolus of apelin induced a significant rise in plasma $\operatorname{AVP}(P=0 \cdot 009)$, ACTH $(P=0 \cdot 012)$, aldosterone $(P=0 \cdot 001)$ and cortisol $(P=0 \cdot 014)$ levels. Levels were increased $15-30 \mathrm{~min}$ postbolus but had returned to time-matched control levels by $60 \mathrm{~min}$. Plasma ANP $(P=0 \cdot 036)$ and BNP $(P<0 \cdot 001)$ were also elevated in response to apelin (Fig. 3). Plasma ANP levels peaked $15 \mathrm{~min}$ following the $1 \mathrm{mg}$ bolus but were still significantly raised $60 \mathrm{~min}$ post-bolus.
Plasma BNP concentrations were increased above timematched control levels at $30 \mathrm{~min}$ following the $100 \mu \mathrm{g}$ dose of apelin and were increased further in response to the $1 \mathrm{mg}$ dose, again remaining significantly above control levels $60 \mathrm{~min}$ post-bolus. Plasma cyclic GMP levels were also significantly increased $(P=0.003)$ in response to apelin, again with levels significantly higher $30 \mathrm{~min}$ following the $100 \mu \mathrm{g}$ dose and further augmented following the $1 \mathrm{mg}$ dose (Fig. 3). Plasma cyclic AMP levels were not affected by the lower two doses of apelin but were significantly raised $(P=0.002)$ in response to the $1 \mathrm{mg}$ bolus (Fig. 3). Apelin administration had no significant effects at any dose on plasma endothelin-1, PRA, norepinephrine, epinephrine or urocortin (Table 1).

Urinary volume and sodium excretion tended to be higher during the apelin arm of the study but this increased output was apparent before the first dose of apelin (Fig. 4). As such, administration of apelin at all three doses had no significant effect on urinary volume, sodium, potassium or creatinine excretion.

\section{Discussion}

Whilst the tissue distribution and range of biological actions reported for apelin suggest a role for the peptide in pressure/volume homeostasis, conflicting reports make the precise role unclear. Furthermore, few integrated studies have been performed and there are no reports of bioactivity of apelin in a large conscious animal model. 


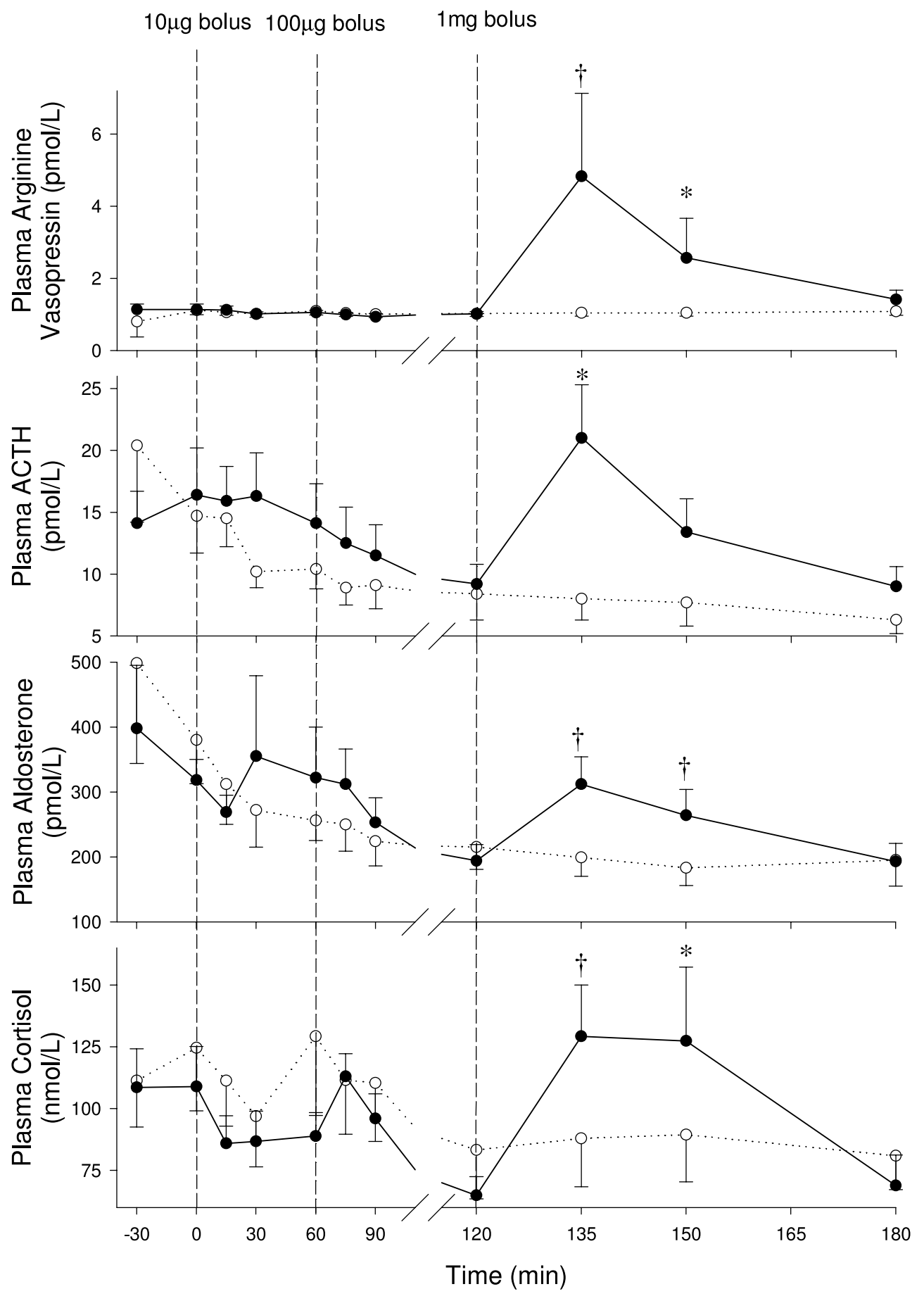

Figure 2 Hypothalamo-pituitary-adrenal axis response to i.v. bolus injections of apelin ( $)$ or vehicle control $(\bigcirc)$ in ten sheep. Values are means \pm S.E.M. Significant differences were observed for plasma arginine vasopressin $(P=0.009)$, adrenocorticotrophin (ACTH) $(P=0.012)$, aldosterone $(P=0.001)$ and cortisol $(P=0 \cdot 014)$. Individual time points significantly different from time-matched control (Fisher's protected LSD) are indicated by ${ }^{*} P<0 \cdot 05$ and $+P<0 \cdot 01$. 


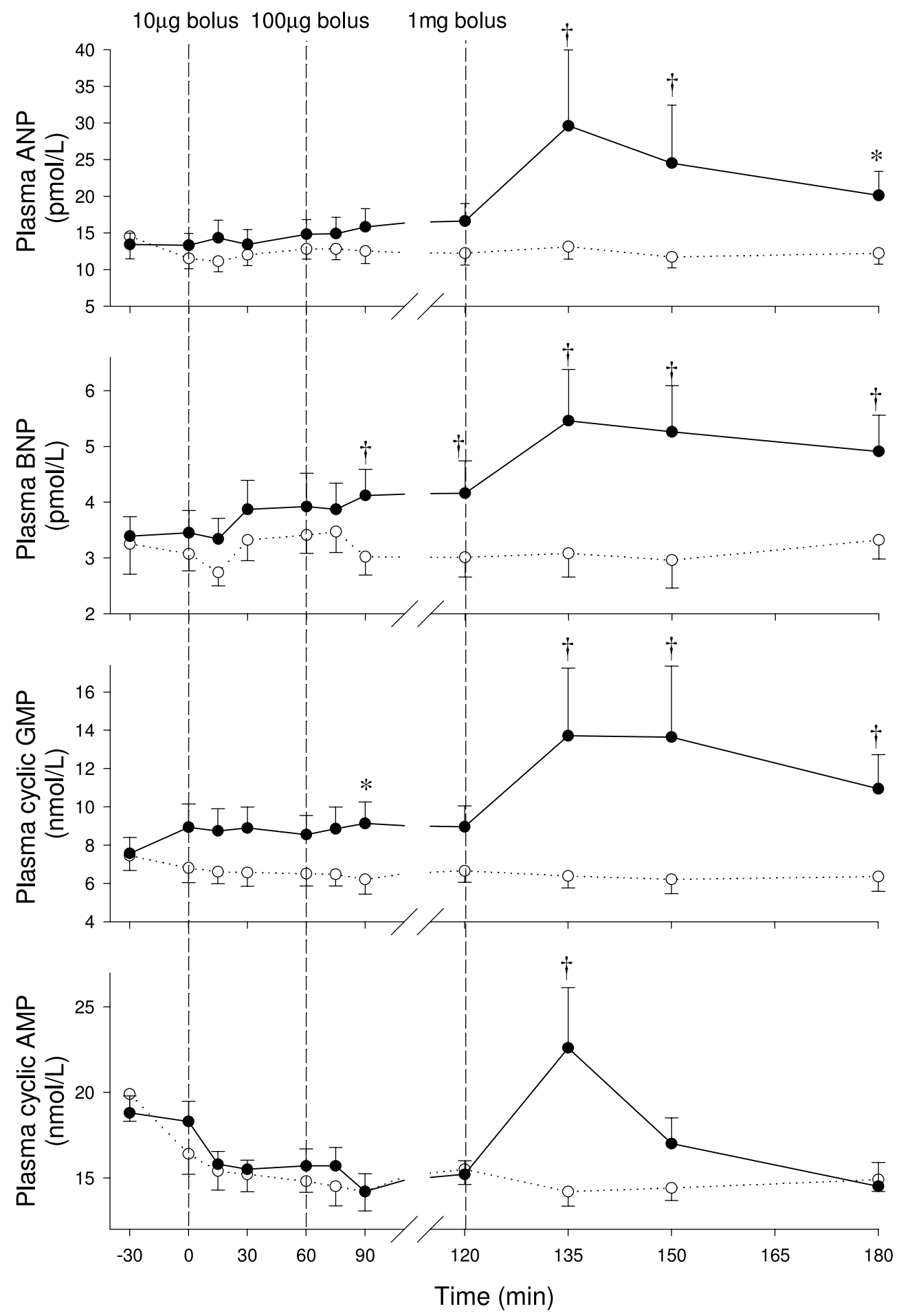

Figure 3 Plasma atrial natriuretic peptide (ANP), brain natriuretic peptide (BNP), cyclic GMP and cyclic AMP response to i.v. bolus injections of apelin $(\mathbf{O})$ or vehicle control $(O)$ in ten sheep. Values are means \pm S.E.M. Significant differences were observed for plasma ANP $(P=0.036)$, BNP $(P<0.001)$, cyclic GMP $(P=0.003)$ and cyclic AMP $(P=0.002)$. Individual time points significantly different from time-matched control (Fisher's protected LSD) are indicated by ${ }^{*} P<0 \cdot 05$ and $+P<0 \cdot 01$. 


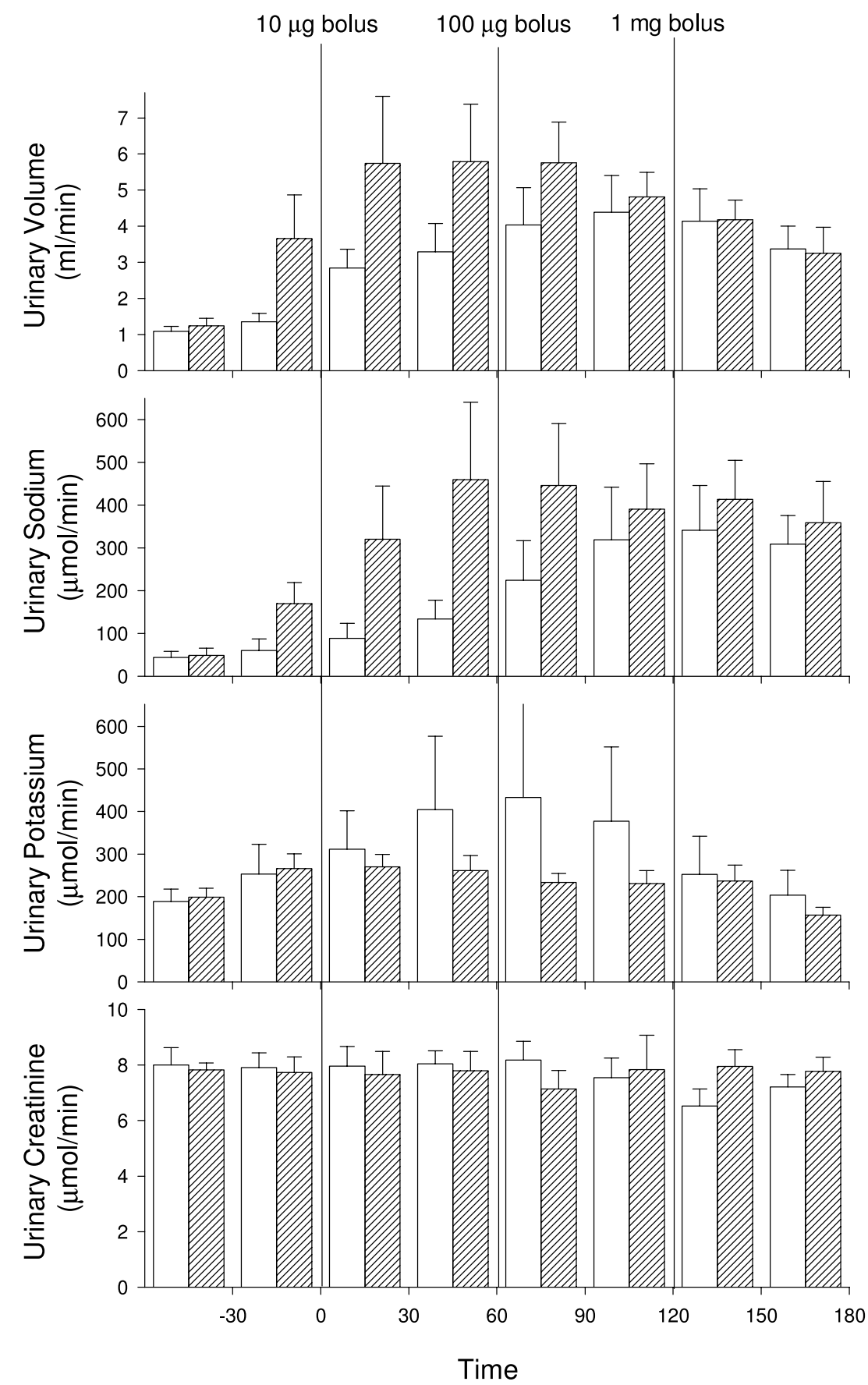

Figure 4 Renal response to i.v. bolus injections of apelin (hatched bars) or vehicle control (open bars) in ten sheep. Values are means \pm S.E.M.

Thus we report the haemodynamic, hormonal and renal effects of apelin in normal conscious sheep. A high i.v. bolus dose $(1 \mathrm{mg})$ of apelin induced a biphasic haemodynamic response characterised by an acute (peak effect 2 min post-bolus) fall in arterial pressure and rise in heart rate followed immediately by a rise in arterial pressure and fall in heart rate. The secondary hypertensive phase was associated with a fall in cardiac output and significant rises in CTPR and RAP. Changes in all haemodynamic indices were short-lived having returned to vehicle control levels by $15-20 \mathrm{~min}$ post-bolus. ECG changes were also observed in four of ten sheep, most notably varying 
degrees of AV block. At this dose, apelin also induced significant activation of the HPA axis with increased plasma AVP, ACTH, aldosterone and cortisol levels peaking by $15 \mathrm{~min}$ post-bolus (first blood sampling timepoint). ANP, BNP, cyclic GMP and cyclic AMP levels were also increased but there was no effect on the other plasma hormones measured or on renal indices.

Previous reports of the effect of apelin on blood pressure are conflicting. Whilst several studies show that apelin lowers arterial pressure in rats (Lee et al. 2000, Tatemoto et al. 2001, Cheng et al. 2003, El Messari et al. 2004), other authors have shown that apelin increases blood pressure (Kagiyama et al. 2005). The current study is the first to report a biphasic response of arterial pressure to apelin. Of interest, similar biphasic responses of MAP (immediate hypotension followed by more prolonged hypertension) have been noted for other vasoactive peptides such as endothelin (King et al. 1990, Rohmeiss et al. 1990) and urotensin II (Gardiner et al. 2004). The initial hypotensive response to the $1 \mathrm{mg}$ bolus of apelin was rapid in onset and peaked at $2 \mathrm{~min}$. This is consistent with other reports of blood pressure lowering by apelin where the peak effect was observed $0 \cdot 5-1$ min post injection and pressures had returned to baseline by 2-4 $\min$ (Lee et al. 2000, 2005, Tatemoto et al. 2001), and may occur via a nitric oxide dependent mechanism (Tatemoto et al. 2001). By contrast, the secondary hypertensive response might be attributed to the activation of hydrogen/sodium and sodium/calcium exchangers in the vasculature as previously reported for apelin in the myocardial sarcolemma (Szokodi et al. 2002). Clearly, further studies examining underlying mechanisms are required.

The reasons for the different reported haemodynamic responses are unclear but may relate to species, dose and the structure of apelin administered. Prior studies were performed in rats, either anaesthetised (Lee et al. 2000, 2005, Tatemoto et al. 2001, El Messari et al. 2004) or conscious (Cheng et al. 2003). To our knowledge, this is the first report of the effect of apelin on MAP in a large animal model (conscious sheep). In the present study, the 10 and $100 \mu \mathrm{g}$ doses of apelin had no effect and only the $1 \mathrm{mg}$ dose induced the biphasic response on MAP and heart rate. A $1 \mathrm{mg}$ bolus in sheep is equivalent to approximately $20 \mu \mathrm{g} / \mathrm{kg}$. Of note, doses employed in the studies that showed only a fall in MAP were generally lower being 3-15 $\mu \mathrm{g} / \mathrm{kg}$ (Lee et al. 2000, 2005, Tatemoto et al. 2001, El Messari et al. 2004). The authors who reported that i.v. apelin increased MAP used markedly higher doses than those employed in the present study (approximately 100 and $250 \mu \mathrm{g} / \mathrm{kg}$ ); however they presented no information on the time-course of effects making it unclear as to whether the hypertensive response was preceded by a fall in MAP (Kagiyama et al. 2005). Cheng et al. (2003) employed doses spanning those effective in sheep $(15-60 \mu \mathrm{g} / \mathrm{kg})$ and reported only a fall in MAP, but again with no time-course information reported. Thus, it is possible that the effects of apelin on MAP are dose- and time-dependent and careful consideration should be paid to the time-course of effects in future studies.

Another possible explanation for differences in haemodynamic responsiveness to apelin may be related to the structure of the apelin administered. Mature apelin is likely derived from the C-terminal region of the propeptide as either a 36 or a 13 amino acid peptide. A wide range of apelin peptides has been administered in previous studies producing variable results. Tatemoto et al. (2001) found that the rank order of potency of three different apelin peptides for lowering MAP in rats was apelin$12>$ apelin-13>apelin-36. By contrast, Lee et al. (2005) reported that apelin-13 lowers MAP in spontaneously hypertensive rats with more potency than apelin-12. Others have shown that apelin-17 is more potent than apelin-13 at lowering MAP in rats (El Messari et al. 2004). Thus, it is possible that different length apelin peptides have differing affinities for the APJ receptor. Moreover, it is also possible that peptide effects differ depending on species and/or vascular bed.

Previous studies reported that hypotensive actions of apelin were associated with either no change (Tatemoto et al. 2001, Lee et al. 2005) or a rise in heart rate (Lee et al. 2000, Cheng et al. 2003, El Messari et al. 2004). In the present study, changes in MAP were associated with mirror-image changes in heart rate, namely an acute rise in heart rate during the hypotensive phase $(2 \mathrm{~min}$ postbolus) followed by a fall in heart rate during the ensuing hypertensive phase. Given the similar biphasic timecourse but directionally opposite changes in MAP and heart rate, it seems likely that changes in heart rate were baroreceptor mediated. This concurs with data showing that apelin-induced increases in heart rate are abolished in ganglion-blocked rats (Cheng et al. 2003). Cheng et al. (2003) also showed in ganglion-blocked rats that mean circulatory filling pressure is reduced by apelin, suggesting that it is a venodilator. In contrast, apelin has been shown to be a potent constrictor of isolated human saphenous veins (Katugampola et al. 2001). Results from the present study give no evidence that apelin is a venodilator, but rather, the $1 \mathrm{mg}$ dose induced a consistent, immediate rise in RAP. Methodology (thermodilution) did not allow rapid (within 1-2 min) measurement of cardiac output in the present study with the first measurements being made at 5-min intervals following bolus administration. Thus, cardiac output was not determined during the acute hypotensive phase ( $2 \mathrm{~min}$ ) but was significantly reduced during the hypertensive phase ( $5 \mathrm{~min}$ post-bolus). This coincided with a significant rise in CTPR, suggesting that a rise in cardiac afterload contributed to the decline in cardiac output. Clearly, mechanisms underlying the effects of apelin on cardiac output are complex and require further study. Results from the current study clearly show that apelin can have an effect on cardiac 
electrophysiology. Whether apelin causes this effect by acting directly on the heart at the level of the sinus node and/or AV node, or whether its effects are mediated via the central nervous system is uncertain. To our knowledge there are no other reports of such an effect for apelin.

Contrasting reports on the effect of apelin on AVP have been published, with apelin inducing an increase in AVP secretion from hypothalamic explants (Taheri et al. 2002) but a reduction in AVP release reported in vivo in response to i.c.v. apelin (Reaux et al. 2001, De Mota et al. 2004). In the present study, the $1 \mathrm{mg}$ apelin bolus elevated plasma AVP along with an increase in circulating levels of the other HPA hormones, namely plasma ACTH, aldosterone and cortisol. These results are consistent with previous reports showing apelin increases ACTH (Taheri et al. 2002) and corticosterone (Taheri et al. 2002, Jaszberenyi et al. 2004) release in vivo. It is likely that the observed rise in aldosterone levels was secondary to the ACTH rise, as PRA levels did not change. Plasma ANP and BNP levels were also raised in response to apelin. Interestingly, plasma BNP levels were significantly higher than time-matched controls during the $30 \mathrm{~min}$ preceding the $1 \mathrm{mg}$ dose and were further augmented in response to the high dose. There was a similar trend for plasma ANP levels to rise before the $1 \mathrm{mg}$ dose, but this rise did not achieve statistical significance. Thus, it is possible that the threshold for apelin's effect on the natriuretic peptides is lower than that for its other biological actions. To our knowledge, there have been no other reports of apelin affecting the natriuretic peptides. Cyclic GMP is the intra-cellular second messenger for the natriuretic peptides so it seems likely, given the same time-course of response, that increased cyclic GMP levels are secondary to changes in ANP and BNP. Of note, plasma cyclic GMP levels were positively correlated with plasma ANP levels in the present study $(P<0 \cdot 001)$. Cyclic AMP levels were also significantly raised following the $1 \mathrm{mg}$ apelin bolus. This is in contrast to previous reports showing that apelin inhibits cyclic AMP production (Reaux et al. 2001, El Messari et al. 2004). We cannot discount the possibility that rises in cyclic AMP observed in the present study were secondary to rises in other hormones, such as $\mathrm{ACTH}$, for which there is a positive correlation in the present study $(P<0 \cdot 001)$. Despite apelin being reported to have a diuretic effect, consistent with its presence in the hypothalamus where it seems to inhibit vasopressin-releasing neurons (De Mota et al. 2004), apelin had no significant effect on any renal indices measured in the present study.

In conclusion, high dose (1 $\mathrm{mg}$ bolus) administration of apelin to normal conscious sheep induces a significant biphasic response in MAP and heart rate, namely immediate hypotension with tachycardia followed by hypertension and bradycardia. This biphasic response in MAP and heart rate was associated with rises in RAP and CTPR and a fall in cardiac output during the hypertensive phase. This dose of apelin was also associated with activation of the HPA axis (possibly secondary to haemodynamic effects) and activation of the natriuretic peptides. Taken together, these results suggest a potential role for apelin in pressure/volume homeostasis. Further studies are required with careful attention being given to structure/activity relationships and dose responses in different species.

\section{Acknowledgements}

We are grateful to the staff of the Christchurch School of Medicine and Health Sciences Animal Laboratory for assistance with animal studies and the Christchurch Cardioendocrine Laboratory staff for hormone assays. Support was provided through grants from the National Heart Foundation of New Zealand and the Health Research Council of New Zealand. The authors declare that there is no conflict of interest that would prejudice the impartiality of this scientific work.

\section{References}

Ashley EA, Powers J, Chen M, Kundu R, Finsterbach T, Caffarelli A, Deng A, Eichorn J, Mahajan R, Agrawal R et al. 2005 The endogenous peptide apelin potently improves cardiac contractility and reduces cardiac loading in vivo. Cardiovascular Research $6573-82$.

Berry MF, Pirolli TJ, Jayasankar V, Burdick J, Morine KJ, Gardner TJ \& Woo J 2004 Apelin has in vivo inotropic effects on normal and failing hearts. Circulation 110 Suppl II 187-193.

Charles CJ, Espiner EA, Cameron VA \& Richards AM 1990 Hemodynamic, renal, and endocrine actions of ANF in sheep: effect of 24-h, low-dose infusions. American Journal of Physiology 258 R1279-R1285.

Cheng X, Cheng XS \& Pang CCY 2003 Venous dilator effect of apelin, an endogenous peptide ligand for the orphan APJ receptor, in conscious rats. European Journal of Pharmacology 470 171-175.

De Mota N, Reaux-Le Goazigo A, El Messari S, Chartrel N, Roesch D, Dujardin C, Kordon C, Vaudry H, Moos F \& Llorens-Cortes C 2004 Apelin, a potent diuretic neuropeptide counteracting vasopressin actions through inhibition of vasopressin neuron activity and vasopressin release. PNAS 101 10464-10469.

Donald RA 1977 Radioimmunoassay of corticotropin (ACTH). In Handbook of Radioimmunoassay, pp 319-390. Ed G Abrahams. New York and Basel: Marcel Dekker.

Dunn PJ \& Espiner EA 1976 Outpatient screening tests for primary aldosteronism. Australian and New Zealand Journal of Medicine 6 131-135.

El Messari S, Iturrioz X, Fassot C, De Mota N, Roesch D \& Llorens-Cortes C 2004 Functional dissociation of apelin receptor signaling and endocytosis: implications for the effects of apelin on arterial blood pressure. Journal of Neurochemistry 90 1290-1301.

Gardiner SM, March JE, Kemp PA \& Bennet T 2004 Bolus injection of human urotensin II in conscious rats evokes a biphasic haemodynamic response. British Journal of Pharmacology $143422-430$.

Goldstein DS, Feuerstein G, Izzo JL, Kopin IJ \& Keiser HR 1981 Validity and reliability of liquid chromatography with electrochemical detection for measuring plasma levels of norepinephrine and epinephrine in man. Life Sciences 28 267-275.

Jaszberenyi M, Bujdoso E \& Telegdy G 2004 Behavioural, neuroendocrine and thermoregulatory actions of apelin-13. Neuroscience 129 811-816. 
Kagiyama S, Fukuhara M, Matsumura K, Lin Y, Fujii K \& Iida M 2005 Central and peripheral cardiovascular actions of apelin in conscious rats. Regulatory Peptides 125 55-59.

Katugampola SD, MacGuire JJ, Mathewson SR \& Davenport AP $2001\left[{ }^{125} \mathrm{I}\right]-\left(\mathrm{Pyr}^{1}\right)$ Apelin-13 is a novel radioligand for localizing the APJ orphan receptor in human and rat tissues with evidence for a vasoconstrictor role in man. British Journal of Pharmacology $1321255-1260$.

Kawamata Y, Habata Y, Fukusumi S, Hosoya M, Fujii R, Hinuma S, Nishizawa N, Kitada C, Onda H, Nishimura O et al. 2001 Molecular properties of apelin: tissue distribution and receptor binding. Biochimica et Biophysica Acta 1538 162-171.

King AJ, Pfeffer JM, Pfeffer MA \& Brenner BM 1990 Systemic hemodynamic effects of endothelin in rats. American Journal of Physiology 258 H787-H792.

Kleinz MJ, Skepper JN \& Davenport AP 2005 Immunocytochemical localisation of the apelin receptor, APJ, to human cardiomyocytes, vascular smooth muscle and endothelial cells. Regulatory Peptides $126233-240$.

Lee DK, Cheng R, Nguyen T, Fan T, Kariyawasam AP, Liu Y, Osmond DH, George SR \& O'Dowd BF 2000 Characterization of apelin, the ligand for the APJ receptor. Journal of Neurochemistry 74 34-41.

Lee DK, Saldivia VR, Nguyen T, Cheng R, George SR \& O'Dowd BF 2005 Modification of the terminal residue of apelin-13 antagonizes its hypotensive action. Endocrinology 146 231-236.

Lewis JG, Manley L, Whitlow JC \& Elder PA 1992 Production of a monoclonal antibody to cortisol: application to a direct immunosorbent assay of plasma. Steroids 57 82-85.

Lun S, Espiner EA, Nicholls MG \& Yandle TG 1983 A direct radioimmunoassay for aldosterone in plasma. Clinical Chemistry $29268-271$.

O'Carroll AM \& Lolait SJ 2003 Regulation of rat APJ receptor messenger ribonucleic acid expression in magnocellular neurons of the paraventricular and supraoptic nuclei by osmotic stimuli. Journal of Neuroendocrinology 15 661-666.

O'Carroll AM, Don ALJ \& Lolait SJ 2003 APJ receptor mRNA expression in the rat hypothalamic paraventricular nucleus: regulation by stress and glucocorticoids. Journal of Neuroendocrinology 15 1095-1101.

Pemberton CJ, Yandle TG, Charles CJ, Rademaker MT, Aitken GD \& Espiner EA 1997 Ovine brain natriuretic peptide in cardiac tissues and plasma: effects of cardiac hypertrophy and heart failure on tissue concentration and molecular forms. Journal of Endocrinology $155541-550$
Rademaker MT, Cameron VA, Charles CJ, Espiner EA, Nicholls MG, Pemberton CJ \& Richards AM 2000 Neurohormones in an ovine model of compensated postinfarction left ventricular dysfunction. American Journal of Physiology 278 H731-H740.

Rademaker MT, Charles CJ, Espiner EA, Fisher S, Frampton CM, Kirkpatrick CMJ, Lainchbury JG, Nicholls MG, Richards AM \& Vale WW 2002 Beneficial hemodynamic, endocrine, and renal effects of urocortin in experimental heart failure: comparison with normal sheep. Journal of the American College of Cardiology 40 1495-1505.

Reaux A, De Mota N, Skultetyova I, Lenkei Z, El Messari S, Gallatz K, Corvol P, Palkovits M \& Llorens-Cortes C 2001 Physiological role of a novel neuropeptide, apelin, and its receptor in the brain. Journal of Neurochemistry 77 1085-1096.

Rohmeiss P, Photiadis J, Rohmeiss S \& Unger T 1990 Hemodynamic actions of intravenous endothelin in rats: comparison with sodium nitroprusside and methoxamine. American Journal of Physiology 258 H337-H346.

Sadler WA, Lynskey C, Gilchrist N, Espiner EA \& Nicholls MG 1983 A sensitive radioimmunoassay for measuring plasma antidiuretic hormone. New Zealand Medical Journal 96 959-963.

Szokodi I, Tavi P, Foldes G, Voutilainen-Myllyla S, Ilves M, Tokola H, Pikkarainen S, Piuhola J, Rysa J, Toth M et al. 2002 Apelin, the novel endogenous ligand of the orphan receptor APJ, regulates cardiac contractility. Circulation Research 91 434-440.

Taheri S, Murphy K, Cohen M, Sujkovic E, Kennedy A, Dhillo W, Dakin C, Sajedi A, Ghatei M \& Bloom S 2002 The effects of centrally administered apelin-13 on food intake, water intake and pituitary hormone release in rats. Biochemical and Biophysical Research Communications 291 1208-1212.

Tatemoto K, Hosoya M, Habata Y, Fuji R, Kakewaga T, Zou M, Kawamata Y, Fukusumi S, Hinuma S, Kitada C et al. 1998 Isolation and characterization of a novel endogenous peptide ligand for the human APJ receptor. Biochemical and Biophysical Research Communications 251 471-476.

Tatemoto K, Takayama K, Zou M, Zhang W, Kumano K \& Fujimiya M 2001 The novel peptide apelin lowers blood pressure via a nitric oxide-dependent mechanism. Regulatory Peptides 99 87-92.

Received in final form 26 February 2006

Accepted 6 March 2006

Made available online as an Accepted Preprint

13 March 2006 